http://jmscr.igmpublication.org/home/ ISSN (e)-2347-176x ISSN (p) 2455-0450

crossref DOI: https://dx.doi.org/10.18535/jmscr/v7i10.37

\title{
Comparative Analysis of Some Cardiovascular Parameters in Medical Students of Pamo University of Medical Sciences
}

\author{
Authors \\ Umoren E.B. ${ }^{1}$, Etim, O. E. ${ }^{2}$, Kolawale, T.A. ${ }^{1}$, Ekpenyong J.F. ${ }^{3}$ \\ ${ }^{1}$ Department of Physiology, ${ }^{2}$ Department of Biochemistry, PAMO University of Medical Sciences \# 1, Tap \\ Road, Elelenwo off Aba Expressway, Port Harcourt, Rivers State, Nigeria \\ ${ }^{3}$ Department of Zoology and Environmetal Biology University of Calabar, Cross River State, Nigeria
}

\begin{abstract}
The effect of exercise on Blood Pressure (BP), Heart rate (HR) and Mean Arterial Pressure (MAP) in 60 young medical students (30 females and 30 males) with Body Mass Index greater than 30 were studied. The subjects were in the age range of 19-23 years with mean age of 22.30 \pm 1.4 years. Blood pressure was measured, using the sphygmomanometer/ ausculatory method. Heart rate was determined from palpitating the radial pulse. The systolic and diastolic blood pressure was compared between the male and female students. The result showed that the female systolic and diastolic blood pressure was higher (120/85 $\mathrm{mmHg}$ ) as compared to the male group with $(90 / 62 \mathrm{mmHg})$. Pulse pressure and MAP were also higher in female $(72.03 \pm 1.87)$ and $(75.10 \pm 1.89)$ respectively as compared to the male group with (72.07 $\pm 1.57)$ and $(72.20 \pm 1.59)$ respectively. Blood pressure responses to different body postures shows a significant increase $(P<0.05)$ in the female students as compared to their male counterpart. BMI in the male students showed an increase of $\left(22.75 \pm 0.48 \mathrm{~kg} / \mathrm{m}^{2}\right)$ as compared to the female students with $(21.94$ $\pm 0.68 \mathrm{~kg} / \mathrm{m}^{2}$ ) BMI. From the results obtained, it was observed that the carotid pulse, radial pulse, blood pressure, heart rate and mean arterial pressure in female subject at different body postures was significantly higher $(P<0.05)$ when compared to their female counterpart. This may be attributed to the size of their heart which is typically smaller in females than in males. However, this difference was not statistically significant when compared with the normal standard values. Results also showed that height, body weight, and BMI for the male subject were higher, though not statistically significant when compared to the female subject. In conclusion, the values obtained in assessing the various cardiovascular parameters in our subjects under investigation appeared normal when compared to standard values. This implies that the subjects are healthy and clinically fit to undergo and complete their chosen area of studies. They are also not prone to obesity, a situation that may predispose them to hypertension, cardiovascular complications and other health problems in future which may result in abrupt cessation of studies.
\end{abstract}

Keyword: Blood pressure, Heart rate, Body mass index, Hypertension, PAMO University Students of medical Sciences.

\section{Introduction}

Hypertension, also known as high blood pressure, is a long-term medical condition in which the blood pressure in the arteries is persistently elevated (Naish and Court, 2014). High blood pressure typically does not cause symptoms 
(CDC, 2015). Long-term high blood pressure, however, is a major risk factor for coronary artery disease, stroke, heart failure, arterial fibrillation, peripheral vascular disease, vision loss, chronic kidney disease, and dementia (Lackland and Weber, 2015; Mendis et al. 2011; Hernandorena et al. 2017 and Lau et al. 2017).

High blood pressure affects between 16 and $37 \%$ of the population globally (Poulter et al 2015). In 2010, hypertension was believed to have been a factor in $18 \%$ of all deaths globally (Campbell et al. 2015).

Overweight and obesity are defined as abnormal or excessive fat accumulation that prevents a risk to health. A crude population measure of obesity is the body mass index (BMI), a person's weight (in kilograms) divided by the square of his or her height (in meters). A person with a BMI of 30 or more is generally considered obese. A person with a BMI equal to or more than 25 is considered overweight (WHO, 2019)

Overweight and obesity are major risk factors for a number of chronic diseases, including diabetes, cardiovascular diseases and cancer. Once considered a problem only in high income countries, Overweight and obesity are now dramatically on the rise in low-and middle-income countries, particularly in urban settings. (WHO, 2019). This correlates positively with the Westernization of diet and rapid emergence of fast food and confectionaries which are highly patronized by young adults especially of the higher socioeconomic group. Hypertension also called "silent killer" have no warning signs or symptoms and for this reason, it is essential that blood pressure is measured regularly. It is in view of this current situation that necessitates this present study as it would provide baseline data for our environment.

\section{Materials and Methods}

Sixty subjects (30 males and 30 females) in the age range of 19- 23 years of PAMO University of Medical Sciences took part in the study. The Body Mass Index (BMI) was determined according to the method by Kathleen, 2006). BMI is a simple mathematical formula, based on height and weight that is used to measure fatness. Weight was measured with light clothes on using a calibrated beam scale placed on a firm surface and height measured using a meter rule. BMI greater than 30 was considered obese.

In this study, subjects were divided into two groups, male and female. The informed consent of the subjects was obtained and subjects responded to a standard questionnaire to obtain information on lifestyle, eating habit and health status. Ethical and Institutional approvals were obtained.

The carotid pulse was taken with the subject supine and the trunk slightly elevated. The pulse was felt with finger and the beats were recorded per minute.

The radial pulse was determined by placing the fingers on the dorsal arm of the forearm. Radial artery pulse alongside its beats was recorded per minute.

The arterial blood pressure was measured using sphygmomanometer and a properly sized pressure cuff. The ausculatory method was used to determine the systolic and diastolic pressure.

Seated blood pressure was measured using sphygmomanometer/ Ausculatory methods. The subject sat in a vertical upright position and the pulse rate was taken by placing two fingers directly above the radial artery and the thumb was placed on the dorsal part of the hand, the pulse was felt and recorded for exactly one minute. The same procedure was repeated on the subject in a horizontal supine position. The subject sat in a vertical upright position and the blood pressure was taken. The same procedure was also repeated on a subject in a horizontal supine position. The subject rode the bicycle for about 10 minutes. All procedures were carried out thrice to compare results and also obtain the mean value.

The cardiovascular response to exercise was assessed using the sport bicycle. The subjects were asked to perform exercise on a cyclic ergometer for 10 minutes at a rate of $10-15$ cycles per minute. The pulse rate, heart rate and 
blood pressure were taken and recorded. Blood pressure was expressed as mean systolic blood pressure $\pm \mathrm{SD} \mathrm{mmHg}$ and mean diastolic blood pressure $\pm \mathrm{SD} \mathrm{mmHg}$.

For the purpose of this study, systolic blood pressure greater than $140 \mathrm{mmHg}$ and diastolic blood pressure greater than $90 \mathrm{mmHg}$ was regarded as hypertension

\section{Statistical Analysis}

Results were given in mean \pm standard error of the mean (SEM). All statistical analyses were performed using the student t-test and chi square with SSPS 13 computer software. $\mathrm{p}<0.05$ was considered as statistically significant.

\section{Results}

Table 1 shows the value of Radial pulse (RP), Carotid pulse (CP), Radial Blood Pressure (RBP) to be $72.03 \pm 1.57,72.20 \pm 1.59,90 / 62 \mathrm{mmHg}$ in males and $72.07 \pm 1.87,75.10 \pm 1.89,120 / 85 \mathrm{mmHg}$ in females and this was however higher though not statistically significant than in male group respectively. The BMI, Height and Weight in male subjects were $22.8 \pm 0.5 \mathrm{Kg} / \mathrm{m}^{2}, 1.7 \pm 1.10 \mathrm{~m}$ and $61.5 \pm 3.10 \mathrm{Kg}$ respectively. This was however, higher though not statistically significant than in female with $21.94 \pm 0.68 \mathrm{Kg} / \mathrm{m}^{2}$, $1.6 \pm 1.0 \mathrm{~m}$ and $57.1 \pm 2.80 \mathrm{Kg}$ respectively.

Table 2 shows blood pressure values at different body postures. Heart rate (HR) and Mean Arterial
Pressure (MAP) in sitting posture for females was higher $(\mathrm{P}<0.05)$ though not statistically significant $73.03 \pm 1.64 \mathrm{bpm}$ and $95.07 \pm 1.04$ $\mathrm{mmHg}$ respectively as compared to the males $71.70 \pm 1.83 \mathrm{bpm}$ and $94.77 \pm 1.04 \mathrm{mmHg}$. HR and MAP in lying down posture for females was higher $(\mathrm{p}<0.05)$ though not statistically significant $74.67 \pm 1.06 \mathrm{bpm}$ and $92.57 \pm 1.64$ $\mathrm{mmHg}$ respectively as compared to the males $70.47 \pm 1.64 \mathrm{bpm}$ and $90.47 \pm 1.54 \mathrm{mmHg}$ respectively. HR and MAP after exercising for females was also higher $(\mathrm{P}<0.05)$ though not statistically significant $112.27 \pm 1.15 \mathrm{bpm}$ and $111.73 \pm 1.65 \mathrm{mmHg}$ respectively when compared to the males with $110.53 \pm 1.34 \mathrm{bpm}$ and $105.80 \pm$ $1.16 \mathrm{mmHg}$ respectively.

Table 3 shows the level of significance in $\mathrm{BP}$ and MAP at $\mathrm{P}<0.05$ between the subjects. HR of $75.37 \pm 1.16 \mathrm{bpm}$ and MAP of $94.92 \pm 1.65$ $\mathrm{mmHg}$ was the level of significant difference in sitting posture between the male and female groups. HR of $72.57 \pm 0.83 \mathrm{bpm}$ and MAP of $91.48 \pm 1.16 \mathrm{mmHg}$ was the level of significant difference in lying posture between the male and female groups. HR of $111.40 \pm 1.61$ and MAP of $108.77 \pm 1.08 \mathrm{mmHg}$ was the level of significant difference during exercising between the male and female groups.

Table 1: Blood pressure of subjects

\begin{tabular}{|l|c|c|c|c|c|c|c|c|}
\hline Sex & Age (yr) & No & $\begin{array}{c}\text { Height } \\
(\mathrm{m})\end{array}$ & $\begin{array}{c}\text { Weight } \\
(\mathrm{Kg})\end{array}$ & $\begin{array}{c}\text { BMI } \\
\left(\mathrm{Kg} / \mathrm{m}^{2}\right)\end{array}$ & RP (bpm) & CP (bpm) & $\begin{array}{c}\text { RBP } \\
(\mathrm{mmHg})\end{array}$ \\
\hline Male & $22.3 \pm 1.4$ & 30 & $1.7 \pm 1.1$ & $61.5 \pm 3.1$ & $22.8 \pm 0.5$ & $72.03 \pm 1.57$ & $72.20 \pm 1.59$ & $90 / 62$ \\
\hline Female & $21.3 \pm 1.3$ & 30 & $1.6 \pm 1.0$ & $57.1 \pm 2.8$ & $21.9 \pm 1.4$ & $72.07 \pm 1.87$ & $75.10 \pm 1.89$ & $120 / 85$ \\
\hline
\end{tabular}

Data are given as mean \pm SEM, *ANOVA $\mathrm{p}<0.05 \mathrm{BMI}=$ body mass index, $\mathrm{RP}=$ radial pulse; $\mathrm{CP}=$ carotid pulse; $\mathrm{RBP}=$ radial blood pressure; $\mathrm{n}=60$

Table 2: Blood pressure of subjects at different body postures

\begin{tabular}{|l|c|c|c|c|c|c|}
\hline Sex & \multicolumn{2}{|c|}{ Sitting } & \multicolumn{2}{c|}{ Lying } & \multicolumn{2}{c|}{ Exercise } \\
\hline & HR & MAP & HR & MAP & HR & MAP \\
\hline Female & $73.03 \pm 1.64$ & $95.07 \pm 1.04$ & $74.67 \pm 1.06$ & $92.57 \pm 1.64$ & $112.27 \pm 1.15$ & $111.73 \pm 1.65$ \\
\hline Male & $71.70 \pm 1.83$ & $94.77 \pm 1.04$ & $70.47 \pm 1.64$ & $90.47 \pm 1.54$ & $110.53 \pm 1.34$ & $105.80 \pm 1.16$ \\
\hline
\end{tabular}

Data are given as mean $\pm \mathrm{SEM}, *$ ANOVA $\mathrm{p}<0.05 \mathrm{HR}=$ heart rate, MAP $=$ mean arterial pressure; $\mathrm{n}=60$ 
Table 3: Level of significance in BP and MAP at $p<0.05$ between male and female

\begin{tabular}{|l|c|c|}
\hline Body Posture & HR (bpm) & MAP (mmHg) \\
\hline Sitting & $75.37 \pm 1.16^{*}$ & $94.92 \pm 1.65^{*}$ \\
\hline Lying & $72.57 \pm 0.83^{*}$ & $91.48 \pm 1.16^{*}$ \\
\hline Exercise & $111.40 \pm 1.61^{*}$ & $108.77 \pm 1.08^{*}$ \\
\hline
\end{tabular}

Data are given as mean \pm SEM, *ANOVA $\mathrm{p}<0.05 ; \mathrm{n}=60$; $\mathrm{HR}=$ heart rate; $\mathrm{MAP}=$ mean arterial blood pressure

\section{Discussion}

Hypertension also called high blood pressure is a condition in which the force of the blood against the artery walls is too high. Blood pressure above $140 / 90$ is defined as hypertension, and pressure above $180 / 120$ is considered severe. Hypertension also called "silent killer" has no warning signs or symptoms, and if left untreated can cause health conditions such as heart disease and stroke. Most people with hypertension are unaware of the problem. And for this reason, it is essential that blood pressure is measured regularly (WHO, 2019).

Blood pressure is usually expressed by two measurements, the systolic and diastolic pressures, which are the maximum and minimum pressures, respectively (CDC, 2015). For most adults, normal systolic and diastolic blood pressures at rest is within the range of $100-130 \mathrm{mmHg}$ and 60 $80 \mathrm{mmHg}$ respectively (Whelton et al. 2017; Mancia et al 2013). For most adults, high blood pressure is present if the resting blood pressure is persistently at or above $130 / 80$ or $140 / 90 \mathrm{mmHg}$ (Poulter et al. 2015; Whelton et al. 2017). Different numbers apply to children (James et al. 2014; Edwin, 2017 and Muyumba et al. 2018).

High blood pressure is classified as either primary (essential) high blood pressure or secondary high blood pressure (Poulter et al. 2015). About 90-95 $\%$ of cases are primary, defined as high blood pressure due to non-specific lifestyle and genetic factors (Poulter et al. 2015; Carretero and Oparil, 2000). $5-10 \%$ of cases are categorized as secondary high blood pressure, defined as high blood pressure due to an identifiable cause, such as chronic kidney disease, narrowing of kidney arteries, an endocrine disorder, or the use of birth control pills (Poulter et al. 2015).
Results of our investigation suggest that the subjects used in this study had normal heart rate and radial blood pressure. This may be attributed to certain quantifiable factors such as the environment (which is quite serene and devoid of pollution) and lifestyle factor. Modifiable risk factors such as unhealthy diets, which include (excessive salt consumption, a diet high in saturated fat and trans fats, low intake of fruits and vegetables), physical inactivity, consumption of tobacco and alcohol, and being overweight or obese are attributive to hypertension. Nonmodifiable risk factors which also include a family history of hypertension; age over 65 years and co-existing diseases such as diabetes or kidney disease, can predispose individual to hypertension (WHO, 2019).

Lifestyle and environmental factors operate interactively to promote hypertension. Essential hypertension is thought to be caused by both genetic and environmental factors. Proposed environmental factors include exposure to chronic stress, obesity, alcohol and salt intake, and physical inactivity (Pickering and Hum, 1997). This position is supported by CDC (2015); Poulter et al. 2015) who had also reported lifestyle factors that increase the risk of hypertension to include excess salt in the diet, excess bodyweight, smoking, and alcohol use. It suffices to state here that the subjects used in the study were devoid of alcohol intake; food intake is highly regimented as their salt intake is strictly regulated by dietician. Alcohol intake is strongly prohibited among students. Subjects are weekly involved in indoor and outdoor physical activities.

From the result of our findings, it was observed that body mass index (BMI) of the subjects was averagely $22.75 \mathrm{Kg} / \mathrm{m}^{2}$ and $21.94 \mathrm{Kg} / \mathrm{m}^{2}$ respectively. This suggests healthiness in the subjects, as healthy range stands at $(18.5-24.9$ $\mathrm{Kg} / \mathrm{m}^{2}$ ). Obesity occurs when a person's BMI is 30 or greater. Obesity is a disorder involving excessive body fat that increases the risk of health problems. It often results from taking in more calories than are burned by exercise and normal 
daily activities. Obesity in young adults has become a significant public health problem because of its impact on the physical and psychological health and because it is a risk factor in the development of chronic cardiovascular and metabolic diseases later in life (Stamler et al., 1978; Cassono et al., 1990; Julius et al., 2000; Rana et al., 2007).

The prevalence of obesity has increased in all ages, genders and ethnic/racial during the past three decades. It is most prevalent in Hispanic males $(27.5 \%)$ and African American females (26.6\%), adolescent and young adults (Ogden et al., 2002). The number of factors responsible for this condition ranges from genetic factors (Rosenbaum and Liebel, 1998), environmental factors such as increased calorie intake and decreased physical activity (Birch and Fisher, 1998), psychological disorders (Barlow and Dietz, 1998; Dietz, 1998; Must and Strauss 1999) and endocrine and genetic syndromes (Edwin, 2017). Obese young adults do less physical activities, prefer sedentary lifestyles and are less tolerant to physical exercises. These attitudes ultimately increase their predisposition to hypertension and other cardiovascular diseases later in life due to continuous deposition of fatty adipose tissue and "quickened" atherosclerotic changes in different blood vessels in their body (Hirsch et al., 1976).

The present study indicates that blood pressure parameters rise to higher levels during exercise. The positive side of this result implies that the subjects used in this study appeared healthy as their radial blood pressure seemed normal, thus were able to go through the exercise regime without any form of suffocation. The body weight was able to cope with the cardiovascular stress and increase in heart rate during the cycling. This feat would not have been possible if subjects were obese. Exercise increases heart and breathing rates, delivering quantities of oxygen from the lungs to the blood, then to exercising muscles (Katherine, 2011). The heart as a muscle, improves its strength as a result of exercise training, particularly with aerobic training (Katherine, 2011).

Comparatively, the blood pressure of the subjects (male and female) suggests that the heart rate and mean arterial pressure in female at different body postures was significantly higher when compared to their male counterpart. This may be attributed to the size of the heart which is typically smaller in females than males. The smaller female heart, pumping less blood with each beat, needs to beat at a faster rate to match the larger male heart's output (Warren, 2019)

\section{Conclusion}

The overall range of values in height, weight, body mass index, carotid pulse, radial pulse, and blood pressure for the subjects used in this study appeared normal. The subjects on the average are not prone to obesity, a situation that would predispose them to hypertension, cardiovascular complications and other health problems in future which may result in abrupt cessation of studies. Our results underscore the need to constantly carry out thorough health checks on the students in other to prevent any loss due to improper health investigations as obtained in some other climes.

\section{References}

1. Barlow, S.E. and Dietz, W.H. (1998): Obesity evaluation and treatment: expert committee recommendations. Pediatrics. 102: E29

2. Birch, L.L. and Fisher, J.O. (1998): Development of eating behaviors among adolescents. Pediatrics. 101:539-549

3. Campbell, N.R., Lackland, D.T., Lisheng, L., Niebylski, M.L., Nilssson, P.M. and Zhang, X.H. (2015): "Using the global burden of disease study to assist development of nation-specific fact sheets to promote prevention and control of hypertension and reduction in dietary salt: a resource from the World Hypertension League". Journal of Clinical Hypertension 17(3): $165-7$. 
4. Carretero, O.A. and Oparil, S. (2000): "Essential hypertension. Part 1: definition and etiology". Circulation. 101(3): 329-35.

5. Cassono, P.A. (1990): Body fat distribution blood pressure, and hypertension: a prospective cohort study of men in the normative aging study. Ann Epidemiol. 1:33-48.

6. CDC (2015): High blood pressure fact sheet". Archived from original on 28 August, 2019. Retrieved 28 August, 2019

7. Dietz, W.H. (1998): Health consequences of obesity in youth: childhood and pediatrics of adult disease. Pediatrics. 101: 503-525

8. Edwin R. (2017): Pediatric Hypertension. Drugs \& Diseaess > Pediatrics: Cardiac Disease and Critical Care Medicine. Updated 3-9-2017 Retrieved 20-9- 2019

9. Hernandorena, I., Duron, E., Vidal, J.S. and Hanon, O. (2017): "Treatment options and considerations for hypertensive patients to prevent dementia". Expert opinion on pharmacotherapy (Review). 18(10): 989 - 1000.

10. Hirsch, J.L. and Bathchelor, B. (1976): Adipose tissue cellularity and human obesity. Clinical Endocrinology and Metabolism. 5: 299-315

11. James, P.A., Oparil, S., Carter, B.L., Cushman, W.C., Dennison-Himmelfarb, C. Handler, J., Lackland, D.T., LeFevre, M.L., Mackenzie, T.D., Ogedegbe, O., Smith, S.C., Svetkey, L.P., Taler, S.J., Townsend, R.R., Wright, J.T., Narva, A.S., and Ortiz, E. (2014): "2014 evidence based guideline for the management of high blood pressure in adults: report from the panel members appointed to the Eighth Joint National Committee (JNC 8)". JAMA. 311(5): 507-20.

12. Julius, S., Valentini, M. and Palatini, P. (2000): Overweight and hypertension: a 2way street? Hypertension. 35: 807-825
13. Katherine, H. (2011): Jumping Heartbeat: Exercise Your Pulse. Bring Science Home. National Science Education Standards: Personal Health Activity 17. Archived from the original on 24-5-2019 Retrieved 22-9-2019

14. Kathleen, M.Z. (2006): How accurate is Body Mass Index, or BMI? New England Journal of Medicine

15. Lackland, D.T. and Weber, M.A. (2015): "Global burden of cardiovascular disease and stroke: hypertension at the core". The Canadian journal of cardiology. 31(5): 569-71

16. Lau, D.H., Nattel, S., Kalman, J.M. and Sanders, P. (2017): "Modifiable Risk Factors and Atrial Fibrillation". Cirulation (Review). 136(6): 583 - 596.

17. Mancia, G., Fagard, R., Narkiewicz, K., Redon, J., Zanchetti, A., Bohm and M. (2013): "2013 ESH/ESC guidelines for the management of arterial hypertension: the Task Force for the management of arterial hypertension of the European Society of Hypertension (ESH) and of the European Society of Cardiology (ESC)". European Heart Journal. 34(28): 2159 - 219.

18. Mendis, S., Puska, P. and Norrving, B. (2011): Global atlas on cardiovascular disease prevention and control (PDF) $\left(1^{\text {st }}\right.$ edn.). Geneva: World Federation and the World Stroke Organization. p. 38. Archived (PDF) from the original on 28-82019 Retrieved 28-8-2019

19. Must, A. and Strauss, R.S. (1999): Risks and consequences of childhood and adolescent obesity. The International Journal of Obesity. 23: S2-S11

20. Muyumba E.K., Dophra, N.N., Clarence, K.M., Jacques, M.M., Placide, K.K. Christian N.K., Oscar, N.L. Francoise, K.J. Justin, K.K., Olivier, M. and Weili, Y. (2018): Oscillometric blood pressure by age and height for non overweight children and adolescents in Lumbumbasi, 
Democratic Republic of Congo. BMC Cardiovascular Disorders. 18: 9

21. Naish, J. and Court, D.S. (2014): "Hypertension" Medical Sciences ( $2^{\text {nd }}$ ed.) pp 562.

22. Ogden, C.L. (2002): Prevalence and trends in overweight among US children and adolescents, 1999-2000. Journal of the American Medical Association 288: 17281732

23. Pickering, T.G. and Hum J. (1997): The effects of environmental and lifestyle factors on blood pressure and the intermediary role of the sympathetic nervous system.

24. Poulter, N.R., Prabhakaran, D., and Caulifield, M. (2015): "Hypertension". Lancet 386(9995): 801-12.

25. Rana, J.S. (2007): Cardiovascular metabolic syndrome - and interplay of obesity, inflammation, diabetes and coronary artery disease. Diabetes Obes Metab

26. Rosenbaun, M. and Liebel, R. (1998): Pathophysiology of childhood obesity Advance Pediatrics. 35: 73-137

27. Stamler, R. (1978): Weight and blood pressure findings in hypertension screening of 1 million Americans. JAMA 240: 1607-1610

28. Warren Rosenberg: What is the difference between male and female Heart Rates? "American Heart Association: Heart Information". Archived from the original on 28 August, 2019. Retrieved 28 August, 2019 https://www.livestrong.com>article

29. Whelton, P.K., Carey, R.M., Aronow, W.S., Casey, D.E., Collins, K.J., Dennison, Himmelfarb, C., DePalma, S.M., Gidding, S., Jamerson, K.A., Jones, D.W., MacLaughlin, E.J., Muntner, P., Ovbiagele, B., Smith, S.C., Spencer, C.C., Stafford, R.S., Taler, S.J., Thomas, R.J., Williams, K.A., Williamson, J.D.,
Wright,

J.T.

(2017):

ACC/AHA/AAPA/ABC/ACPM/AGS/APh A/ASH/ASPS/NMA/PCNA Guideline

for the prevention, Detection, Evaluation, and Management of high blood

pressure in Adults: A Report of the American College of cardiology/

American Heart Association Task Force on clinical practice guidelines".

Hypertension. 71(6): e13-1115 doi: 10.1161/ HYP. 0000000000000065. PMID 29133356

30. World Health Organization (2004): Obesity and endocrine disease. Endocrinology \& Metabolism Clinics of North America 32(4): 895 - 914

31. World Health Organization (2019): Health Topics: Obesity. Archived from the original on 13-9-2019 Retrieved 20-92019

32. World Health Organization (2019): Hypertension. Archived from the original on 13-9-2019 Retrieved 22-9-2019. 